\title{
3D corrective osteotomy of malunited upper limb fractures
}

\author{
Tsuyoshi Murase \\ From 10th Congress of the Asia-Pacific Federation of Societies of Surgery fo the Hand and the 6th Congress \\ of Asia-Pacific Federation of Societies of Hand Therapists \\ Kuala Lumpur, Malaysia. 2-4 October 2014
}

\begin{abstract}
Introduction
Corrective osteotomy for malunited fractures of the upper extremity remains a challenging procedure. Anatomical correction is the key to good clinical outcome after corrective osteotomy for malunited fractures, especially in cases of the upper extremity. To make a precise deformity correction in malunion, we have developed a computer-assisted system for corrective surgery, including a three-dimensional (3-D) program and a patient specific instrument (PMI), and investigated the results of corrective surgery for malunited fractures of the distal radius (MFRD), forearm diaphyses (MFFD) and distal humerus (cubitus varus deformity: CVD) with the use of this technology.
\end{abstract}

\section{Materials and methods}

Ten MFRD, 20 MFFD and 30 CVD were enrolled in this study. Both upper extremities including the whole affected bone were scanned with a CT machine and 3-D bone models were constructed on the computer. Then, the deformity of the affected bone was evaluated by superimposing it with the goal model (e.g., the mirror image of a contralateral normal bone), which can be further determined in terms of rotation around and translation along the 3-D deformity axis using the screw displacement axis technique [1]. With this information, the most appropriate corrective osteotomy was simulated, which could be a closing wedge osteotomy, opening wedge osteotomy or rotational osteotomy. Then, the PMI was designed and manufactured by a 3-D printer with medical grade resin. The PMI has a shape that exactly fits to the bone surface and guides the planned osteotomy and insertion of Kirschner wires that indicated the amount of correction. During the operation,

Department of Orthopaedics, Osaka University Graduate School of Medicine, Suita, 565-0871 Japan
Computer-assisted osteotomy can provide excellent radiographic and clinical outcome for the treatment of malunited fractures of the upper extremity.

For malunited distal radius fracture, a combination of 3-D computer simulation and a volar locking plate provides a simple, systematic and accurate corrective surgery [2].

For malunited diaphyseal forearm fractures, achievement of axial alignment, and restoration of normal length of both bones are considered to be prerequisites for a clinically good outcome. However, malunion with complex 3-D deformities of both forearm bones is difficult to assess accurately by plain radiography. In addition, it is a demanding procedure to reduce two parallel rotating bones while maintaining the congruity of the adjacent joints by corrective surgery. Computer simulation and use of PMI help us to achieve the highly demanding procedure with relatively simple surgical technique [3].

For the cubitus varus deformity after supracondylar fracture that classically includes varus, extension, and 
internal rotation deformity, no reliable surgical method for 3-D corrective osteotomy has been established. Our method using a PMI designed on the basis of 3-D computer simulation realized simultaneous correction of the three deformity components $[4,5]$.

Published: 19 May 2015

\section{References}

1. Murase T, Oka K, Moritomo H, Goto A, Yoshikawa H, Sugamoto K: Threedimensional corrective osteotomy of malunited fractures of the upper extremity with use of a computer simulation system. The Journal of bone and joint surgery. American volume 2008, 90:2375-2389.

2. Miyake J, Murase T, Moritomo H, Sugamoto K, Yoshikawa H: Distal radius osteotomy with volar locking plates based on computer simulation. Clinical orthopaedics and related research 2011, 469:1766-1773.

3. Miyake J, Murase T, Oka K, Moritomo H, Sugamoto K, Yoshikawa H: Computer-assisted corrective osteotomy for maluniteddiaphyseal forearm fractures. The Journal of bone and joint surgery. American volume 2012, 94:e150

4. Murase T, Takeyasu Y, Oka K, Kataoka T, Tanaka H, H Y: Three-dimensional corrective osteotomy for cubitusvarus deformity with use of custommade surgical guides. JBJS Essential Surgical Technique 2014, 4:1-7.

5. Takeyasu Y, Oka K, Miyake J, Kataoka T, Moritomo H, Murase T: Preoperative, computer simulation-based, three-dimensional corrective osteotomy for cubitusvarus deformity with use of a custom-designed surgical device. The Journal of bone and joint surgery. American volume 2013, 95:e1731-1739.

\section{Submit your next manuscript to BioMed Central} and take full advantage of:

- Convenient online submission

- Thorough peer review

- No space constraints or color figure charges

- Immediate publication on acceptance

- Inclusion in PubMed, CAS, Scopus and Google Scholar

- Research which is freely available for redistribution

Submit your manuscript at www.biomedcentral.com/submit 